\title{
Investigating Changes in Demotivation among Chinese EFL Learners from an Activity Theory Perspective
}

\author{
Chili $\mathrm{Li}^{1} \&$ Jinghua Qian ${ }^{2}$ \\ ${ }^{1}$ School of Foreign Languages, Hubei University of Technology, China \\ ${ }^{2}$ Moray House School of Education, University of Edinburgh, UK \\ Correspondence: Chili Li, School of Foreign Languages, Hubei University of Technology, Hongshan District, \\ Wuhan, Hubei Province, China. E-mail: sundaylcl@126.com
}

Received: August 30, 2017 Accepted: September 18, 2017 Online Published: October 25, 2017

doi:10.5539/ijel.v8n1p44

URL: https://doi.org/10.5539/ijel.v8n1p44

\begin{abstract}
This paper reports on a study that investigated the changes of demotivation to learn English over the four college years among Chinese English as a Foreign Language Learners (EFL) from the perspective of Activity Theory. Semi-structured interviews were conducted on fifteen college EFL learners in China. The interview data were analyzed by means of content analysis to explore the changes in the demotivation among the participants and the reasons why their demotivation changed. The results revealed that: 1) the interviewees experienced changes in their demotivation during the four college years, with a stronger demotivation in the first and fourth year; 2) the dynamic disposition of the respondents' demotivation is related to such factors as subject (Interest and future career), object (English examinations), tools (textbooks) and community (peers and teachers). The findings are implicative for teachers and students to tackle demotivation in English class for students at technological universities in China and other similar EFL contexts beyond.
\end{abstract}

Keywords: changes, demotivation, Chinese EFL Learners, activity theory

\section{Introduction}

Demotivation to learn English has drawn decent attention among scholars in the field of second language acquisition in the past two decades. It has been found that demotivation, just as motivation can stimulate the initiative study of language learners, can also have a negative impact on language learning. Research on demotivation to learn English has explored this construct mainly from a static cognitive perspective, little light is shed onto the dynamicity of demotivation. The current study thus aims to bridge this gap by investigating the potential changes in demotivation to learn English among a cohort of Chinese college EFL learners from the perspective of activity theory. This study will cast the light on the dynamic disposition of demotivation in EFL class and be implicative for English language teaching for students at technological universities in China and beyond.

\section{Literature Review}

\subsection{Definition of Demotivation}

Motivation has been viewed as one of the key factors to success in language learning, which not only provides the basic impetus but also develops a long-term learning process. Over the past decades, there are various definitions about motivation while the most acceptable one was represented by Dörnyei \& Ottó (1998). According to them, motivation is a changing arousal in a person that initiates, augments, terminates, and evaluates the cognitive processes whereby primary desires and wishes are prioritized and acted out (successfully or unsuccessfully).

Motivation is divided into two sides: positive and darker sides. The latter can be regarded as the other side of motivation that may diminish motivation, which is known as demotivation. Demotivation is regarded as the decreasing or losing of the motivation. Those EFL learners who decrease or lose their interest towards English learning are said to be the subject of demotivation.

Demotivation is the same crucial as motivation for EFL learners in language learning. It has been found that the motivational factors demonstrated positive correlations with demotivational factors, and that the ideal L2 
(Second Language) self shows the highest correlation with demotivational factors (Kim \& Kim, 2015).

\subsection{Studies on Demotivation to Learn English}

During these years, although most researchers still explore more on the positive side of motivation, the issue about demotivation has caught the attention of plenty of researchers both at home and abroad.

Gorham \& Christophel (1992) initiated the first study on demotivation. 2403 motivators and demotivators were coded and categorized into 20 categories of motivators and 20 categories of demotivators by 208 college students. It turned out that teacher behaviors accounted for almost half of both motivators and demotivators, which could be concluded that lack of motivation is viewed as a teacher-related problem. Gorham \& Millette (1997) compared the different perceptions of sources of motivation and demotivation among teachers and students. They pointed out that those teachers who were confident about their teaching ability had more influences on demotivation.

Hamada (2008) examined 54 second year high school learners and 36 third year junior high students in Japan with questionnaire and in-house test. The study explored the changes of the state of demotivation and the relationship between demotivators and demotivation. It found that communicative method mainly influenced high school students. According to Kim (2009), a new nature of demotivation emerged that both internal and external factors contributed to student demotivation. The study also concluded that difficulty in learning English was the greatest demotivator, reducing motivation and interest.

Falout, Elwood, \& Hood (2009) investigated the relationship between demotivation and English proficiency of EFL learners in Japan. It is concluded that the non-English majors with low English proficiency were least likely to minimize demotivation. Sakai \& Kikuchi (2009) summarized that learning contents and materials and test outcomes factors were the more common demotivating factors for less motivated learners. Hu (2011) surveyed the relationship between demotivation and EFL Learners' English language proficiency and found that learning difficulty was the most important predictor variable. Tsang (2012) identified four demotivational factors: teachers, feedback, difficult of the class and feeling of progress.

Although studies on demotivation in China started later than that abroad, increasingly more studies are published in core journals in the past fifteen years. Li \& Zhou (2017) investigated the demotivation to learn English among Chinese EFL learners from local universities and found that external factors are more influential than the internal ones. Li (2016) compared the demotivation among students of junior high school and senior high school. He found that high school students are less easily influenced than junior school students by such factors as teachers and unhappy learning experience.

In their exploration of the relationship between demotivation and academic fields among Chinese EFL Learners, Li \& Zhou (2017) discovered that English majors were significantly different from the students of International Trade such demotivators as teacher-related factors, teaching environment and reaching facilities, lack of intrinsic interest, and undesired influences of important others. Liu \& Liu (2016) investigated the demotivation among 191 high school students. They discovered seven demotivators and found that girls are more likely be demotivated than boys. However, Cai \& Hou (2013) analyzed the difference in demotivation between male and female college students and found not so much difference between the students.

\subsection{The Dynamicity of Demotivation}

The studies mentioned above all focus on the static description of demotivation and on the identification of the relationship between demotivators and other learner variables. Little attention is paid to the exploration of the dynamic nature of demotivation. Of particular interest are the following studies:

Najafi \& Behjat (2013) explored the rise and fall of motivation among 80 Iranian female students at different levels of language proficiency from high school to university. Their results found that there are five demotivating factors responsible for the rise and fall of motivation for students at different proficiency levels, including learning contents, materials, and facilities; attitude towards English speaking community; the teacher; experience of failure, and attitude towards second language learning.

Kikuchi (2017) examined the changes in demotivation over two semesters among twenty Japanese university freshmen from a Dynamic Systems perspective. The study found that learners had different trajectory and attractor states and experienced different demotivators. He thus suggested taking contexts and various agents such as classmates, senior students and teachers into account when examining demotivation.

Though limited in number, these studies have revealed that demotivation is not a static phenomenon, but a socially situated construct. This construct is related to a multitude of socio-cultural factors. The complex nature 
of demotivation and its relationship with these multiple socio-cultural factors warrant further investigation.

\subsection{Activity Theory}

\subsubsection{The Introduction of Activity Theory}

Activity Theory is an important part of socio-cultural theory with its root in the Soviet Russian cultural-historical school of psychology. Vygotsky (1978) explained Activity Theory based on the notion of mediated action. A further development on Activity Theory was led by Leont'ev (1981), who came up with three different levels of human processes: activity, actions, and operations. The third generation of Activity Theory raised by Engeström (1987) was the most accepted one that was built up on the idea of multiple interacting activity systems.

There are six elements of Activity Theory, which are subject, object, tools, rules, community, and division of labor as follows: Subject, as the main body in an activity, can be either an individual or a collective. In this paper, the subject refers to Chinese College EFL learners. Object is the goal of subject in the specific activity. Take the study for instance, the object can be understood as the language learning outcomes with the influence of demotivation. Tools are the devices that humans use to act on the physical world (Vygotsky, 1978). To achieve the object, subject may use the meditational tools such as textbooks, learning materials and learning environment. Rules refer to regulations, norms and conventions that ensure the successful development of activity system, for example, the rules of classes and the rubrics of courses. Community as a social cultural context consists of multiple individuals who share the common general objectives (Chen \& Johnson, 2016). In the current study, those who have the common objectives are class teachers, peers, especially classmates and roommates. Division of Labor refers to the horizontal division of tasks between the members and the vertical division of power and status (Wu, 2002). In this paper, the analysis is limited to the division of labor within peer works or group works either in class or after class.

\subsubsection{Studies on Demotivation from the Perspective of Activity Theory}

Previous studies have proved the applicability of Activity Theory in studies on Applied Linguistics, and particularly on motivation and demotivation. Yu (2013) revisited teacher feedback and peer feedback within a sociocultural activity-theory perspective. The paper argued that the differences between teacher and peer feedback caused by not only individual action but also the socially constructed and culturally mediated activity. Qin \& Dai (2013) summarized the previous research on L2 motivation and presented a model of Activity Theory to analyze college English learning motivation by investigating 100 freshmen and sophomore. Li (2015) focused on the theoretical perspective of demotivation and introduced the core notion of Activity Theory such as mediation and contradiction into the research on demotivation.

Kim (2011) investigated the longitudinal trajectories of two adult Korean immigrants about how their ESF learning changing from an Activity Theory perspective. The study gave the conclusion that it was not the ESL context but each participant's recognition that played an important role in creating, maintaining, and terminating ESL learning motivation. Kim \& Kim (2013) conducted a study on how demotivation can be conceptualized within the framework of Vygotskian Activity Theory. Both studies gave sufficient academic attention to the potential dynamic interaction between English learners and potential factors for demotivation. However, more empirical evidence is in need to validate the applicability of the activity theory into demotivation studies.

\subsection{The Proposed Theoretical Framework for the Current Study}

The above literature review indicates that some limitations on the previous studies of demotivation. First, most research took demotivation as a static phenomenon and only explored the factors that may have caused demotivation. Secondly, the subjects researched are often middle school students or English major students at universities. However, there has not been sufficient academic attention to non-English major learners. In China, many non-English major students showed a weak interest in studying English after entering college, who should be more likely to be the research subject. Further, little research has examined the dynamic nature of demotivation. In fact, demotivation is a complex, multiple-dimensional, and dynamic (Rashidi, Rahimi, \& Alimorad, 2014). Therefore, this paper proposes to apply Activity Theory to explore the change of demotivation to learn English. It attempts to explain the dynamic process of demotivation from a framework of Activity Theory as follows (Figure 1). 
Figure 1 A Proposed Framework from the Perspective of Activity Theory

Tools: textbooks, learning materials and learning environment

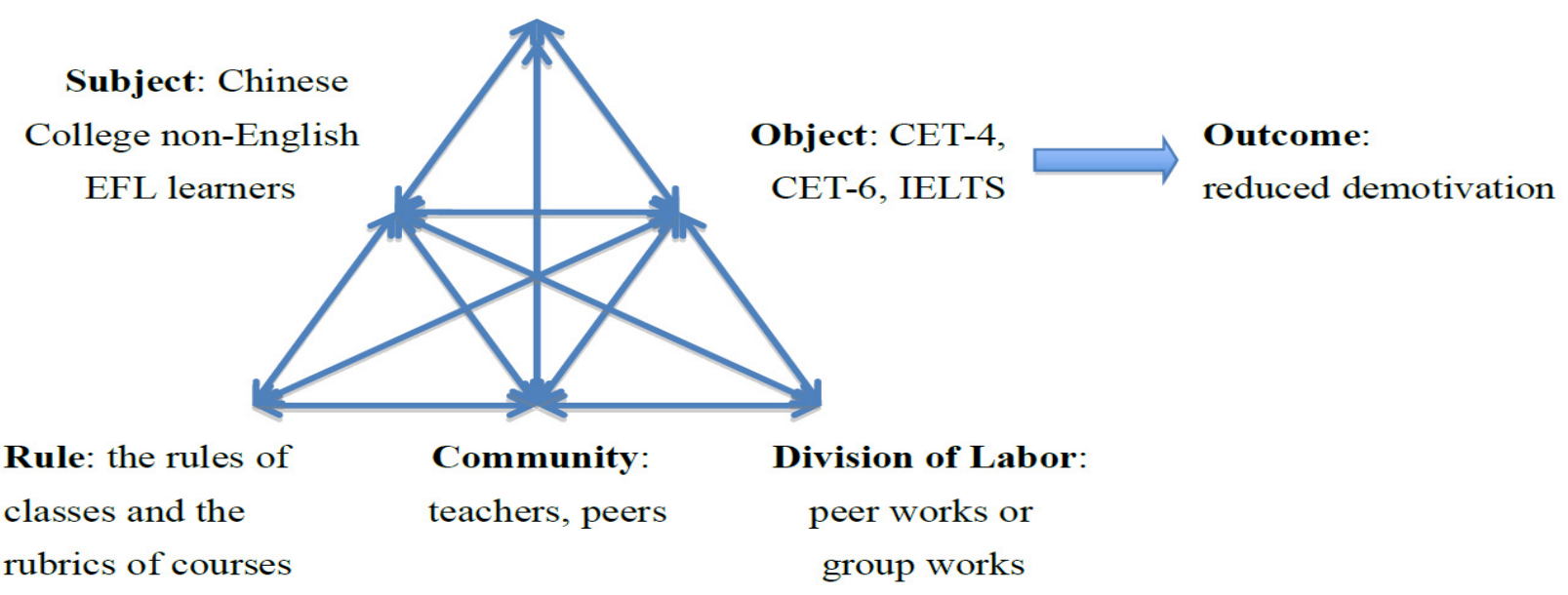

According to this framework, the changes in demotion can be accounted for from the following six aspects:

Subject: Chinese College non-English learners from different schools and majors.

Object: CET-4, CET-6 and any other exams or personal goals.

Tools: textbooks, learning materials and learning environment and other learning tools.

Rules: the rules of classes and the rubrics of courses that can provide a standard on study.

Community: teachers, and peers who may study together.

Division of Labor: division of tasks such as peer tasks or group tasks.

\section{Methodology}

\subsection{Research Questions}

This study aims to explore the changes of demotivation from the perspective of Activity Theory. Accordingly, it mainly tries to find answers to the following questions:

1) Does college EFL learners' demotivation change during the four-year college time? If so, how?

2) To what degree can Activity Theory account for the changes in demotivation of the participants?

\subsection{Research Participants}

The study involved 15 participants from 10 technological universities in China. Among the participants, there were 5 seniors, 8 juniors, and 2 second-year non-English major students. Their majors were Track Traffic Signal and Control, Electronic Science and Technology, Electronic Engineering, and so on. For achieving more accurate research results, the participants had relatively lower English scores. Among the 15 interviewees, 2 of them did not pass CET-4 (College English Test Band 4). Only 1 of them passed CET-6, with a score of 436. 
Table 1. Background information of the participants

\begin{tabular}{llllll}
\hline Number & Student & Gender & Grade & Major & CET-4 Score \\
\hline 1 & A & Male & 4 & Track Traffic Signal and Control & Fail \\
2 & B & Male & 4 & Electronic Science and Technology & 451 \\
3 & C & Male & 4 & Automation & 503 \\
4 & D & Female & 4 & Credit Management & 510 \\
5 & E & Female & 4 & Engineering Supervision & 460 \\
6 & F & Male & 3 & Electronic Commerce & 471 \\
7 & G & Male & 3 & Materials Science and Engineering & 527 \\
8 & H & Female & 3 & Food Science and Engineering & Fail \\
9 & I & Female & 3 & Naval Architecture and Ocean Engineering & 497 \\
10 & J & Male & 3 & Software Engineering & 600 \\
11 & K & Female & 3 & Electronic Science and Technology & 516 \\
12 & L & Female & 3 & Energy Application Engineering & 535 \\
13 & M & Male & 3 & Innovation and Biochemical & 540 \\
14 & N & Male & 2 & Measurement and Control & 543 \\
15 & O & Male & 2 & Automation & Unknown \\
\hline
\end{tabular}

\subsection{Research Instrument}

The instrument for this study is an interview protocol, which is composed of two parts. Part 1 asks the participants' demographic information such as name, gender, school, major and the scores of CET-4, CET-6. Part 2 inquires the interviewees' changes in demotivation from the perspective of Activity Theory. This part mainly includes the following questions:

1) Is there any change in your demotivation to learn English during your college study?

2) Do you think teachers are the most important factor in your English study? Why or why not?

3) How do you think of your English study for final exam at the end of the term?

4) How will the completion of English courses change your attitudes towards English study?

\subsection{Data Collection}

The current study collected its data by means of semi-structured interviews. The interviewees were first asked about their personal information such as name, major, CET-4 and CET-6. Then, the interviewees were required to reflect on their English learning, the change in their attitude towards and interest in English learning at the start and in the end of each semester as well as the summer vacations since they entered university.

Altogether there were 11 time nodes of reflection for the interviewees at Grade 4, while were fewer time nodes of reflection for those sophomore and junior interviewees as they only had 2 or 3 years of university life when this study was conducted. The participants were required to evaluate their demotivation to learn English with three statuses of demotivation: Weak (W), Neither Weak Nor Strong (N) and Strong (S). The weaker the demotivation is, the higher the interest in studying English. The specific reasons for evaluation were required as well.

The Interview Protocol guided all interviews. When found to be vague in the expression, the interviewees would be asked to elaborate further. All the interviews were audio-recorded. Each interview lasted about one hour.

\subsection{Data Analysis}

The collected interview data were transcribed and analyzed using content analysis. The first step was to list all the personal information in the Excel, which included their name, gender, school, major, the score of CET-4 and CET-6. The second step was to transcribe the audio-record. Every single sentence and words should be written down carefully.

The third step was to analyze the status of demotivation in different time nodes. This was to check whether there was a change in demotivation to learn English among the interviewees during four-year college time and how the demotivation changed. This step aims to answer the first research question.

The fourth step was to read and re-read the transcription to identify the factors that might have caused the demotivation. An iterate process of reading, re-rereading, and coding was followed when content analyzing the interview data. This step is set to answer the second research question which is about the degree to which Activity Theory could account for the changes in demotivation of the participants. 


\section{Findings and Discussion}

\subsection{The Changes in Demotivation}

According to Table 2, all the participants had changes in their demotivation on studying English during their college time. And as we had proposed, the changes were more obvious on those specific time nodes: at the start and the end of an academic year, and in the summer vacation.

Nine of the fifteen participants had strong demotivation at the start of college life (September). They were Student C \& D in the time node of 201309, Student F, G, H, J, K and L on 201409, and Student N on 201509. Similarly, most of the students, especially those 3rd and 4th grade students, had strong demotivation at the end of college life. Besides, 12 students had weak demotivation on studying English on the first final examination. They were Student A, B, C, D and E on 201406, Student F, G, H, I, K and M on 201506, and Student N on 201606. But it is also found that a few students (Student C \& F) still had strong demotivation at the end of the term on 201506 and 201606 respectively.

On the summer vacations (July), nearly all the students had strong demotivation. On the first summer vacation, 14 of the 15 students had low interest in learning English, namely, Student A, B, C and E on 201407, Student F, G, H, I, J, K and M on 201507 and Student N \& O on 201607. At some specific time nodes, demotivation changed a little bit from person to person. For example, most participants (Student A, B, C, E, F, G, H, I, K, M, $\mathrm{N}, \mathrm{O}$ ) had weak demotivation at the end of term but had strong demotivation during the summer vacation while some others (Student D, J, L) had not.

To sum up, stronger demotivation seemed to be more likely to be observed in the first and fourth year during the college time. Within an academic year, students' demotivation was more likely to vary from an ordinary level (neither weak nor strong) to weak. Most students had weak demotivation at the end of the term but strong demotivation on summer vacations.

Table 2. Changes in the demotivation among the interviewees

\begin{tabular}{lllllllllllll}
\hline Student & Grade & 201309 & 201406 & 201407 & 201409 & 201506 & 201507 & 201509 & 201606 & 201607 & 201609 & 201701 \\
\hline A & 4 & N & W & S & N & N & S & N & N & S & S & S \\
B & 4 & N & W & S & N & W & N & N & W & S & N & S \\
C & 4 & S & W & S & N & S & S & W & W & W & N & S \\
D & 4 & S & W & W & N & N & N & N & W & W & S & W \\
E & 4 & N & W & S & S & W & S & W & N & W & N & S \\
F & 3 & $/$ & $/$ & $/$ & S & W & S & W & S & S & N & N \\
G & 3 & $/$ & $/$ & $/$ & S & W & S & N & W & N & N & S \\
H & 3 & $/$ & $/$ & $/$ & S & W & S & N & W & N & N & S \\
I & 3 & $/$ & $/$ & $/$ & N & W & S & N & N & S & W & S \\
J & 3 & $/$ & $/$ & $/$ & S & N & S & W & W & N & N & W \\
K & 3 & $/$ & $/$ & $/$ & S & W & S & N & W & N & W & S \\
L & 3 & $/$ & $/$ & $/$ & S & N & S & N & W & N & N & W \\
M & 3 & $/$ & $/$ & $/$ & N & W & S & N & N & S & N & S \\
N & 2 & $/$ & $/$ & $/$ & $/$ & $/$ & $/$ & S & W & S & W & S \\
O & 2 & $/$ & $/$ & $/$ & $/$ & $/$ & $/$ & W & N & S & W & S \\
\hline
\end{tabular}

Note. $* \mathrm{~W}=$ Weak, $\mathrm{N}=$ Neither Weak Nor Strong, $\mathrm{S}=$ Strong.

\subsection{Interpreting Changes in Demotivation from the Activity Theory Perspective}

The interview data were content analyzed with the purpose of interpreting the changes in the demotivation to learn English among the interviewees. The results revealed that, of the six elements of Activity Theory, subject, object, tools and community were found to have more obvious influence on the changes of demotivation in studying English among the participants, while rules and division of labor seemed to be less influential. Therefore, the study would only interpret the changes in demotivation from the perspectives of subject, object, tools, and community.

\subsubsection{Subject}

The subject refers to the 15 non-English major students in this study. When asked why they did not study English with initiative mind, some of those students who had strong demotivation answered that they were not keen in English. Examples are as follows: 
I think unless I have strong interest in English or I will go abroad to study, I won't study English very hard. (Student D)

I am not an English-major student, so I don't need to treat English too seriously. (Student A)

According to the results of the study, it is found that most participants had strong demotivation in the first year but then their demotivation became less strong in the second year. Some of them gave their reasons as follows:

The first two months when I entered the university, I really did not want to study English. I had finished the college entrance examination. I had military training. I had a lot of classes. I also joined Student Union and had plenty of tasks. I was too tired to study English. (Student G)

I didn't have CET-4 exam in the first year. And I believed I could pass the exam, so I didn't study English hard in the first year. (Student E)

Compared to the first year, most participants admitted that they had strong demotivation in the fourth year as well.

I have no time and energy to study English. My job will not need English .... (Student A)

"I am not the English major student" reminds of the study results of Gao (2014). Her study explored the relationship between demotivation and major. Without much relation between English and their major, students would pay less attention to English and English study.

To conclude, subject in demotivation plays a very important role. Once a student has no interest in English, he or she will not pay much attention to English. In addition, if a student doesn't have a goal with English, he won't study English either.

\subsubsection{Object}

Object is the goal of subject in the specific activity. In the current study, object can be carried on the score of English examinations such as CET-4, CET-6, IELTS, and so on. Object is a very important reason for weak demotivation at the end of the term because students need to prepare for the English exams. During the end of term, most students said that they had the weakest demotivation. They spent plenty of time preparing for the final exam so that they would study English very hard.

If I pass the CET-4, I am qualified to get the graduate certification. So, I won't put more emphasis on English. (Student E)

However, a few participants showed a different trend that they had strong demotivation during end of the term and gave the following reasons. It was also about the object, but the object was not about English. Thus, students would put less emphasis on English.

I had a lot of professional courses in sophomore, and those courses were very difficult for me, especially the Linear Algebra, Advanced Mathematics, Macroeconomics, and so on. I was afraid that I might fail the exams, so I spent most of my time on these courses instead of English. (Student D)

Most participants pointed out that their demotivation of studying English became strong on summer vacation, because they thought there was no motivation and/or reason to study English. The examination was over, so they did not have the object of studying English. Just as the study of Li (2014), four internal factors would affect students' demotivation on studying, one of which was lack of interest. An evidence is from Student B as follows:

When it comes to holidays, I don't have too much interest in studying English. Because I have passed the English examination. (Student B)

However, two participants argued that they would have weak demotivation among vacations for they were preparing for the important exams on next semesters such as CET-4 and post-graduate entrance examination. That is the reason several interviewees had weak demotivation in summer vacation too.

Because I had to prepare the post-graduate entrance examination, I made the best use of summer vacation. I studied English every day. (Student E)

And for some participants, they may be influenced by the English movies or songs. In this part, object is the goal to understand the stories or lyrics. It might appear a situation that they had a weak demotivation sometimes.

Sometimes, I like listening to English songs, which make me want to understand their lyrics. (Student B)

Similarly, student B revealed another object that is very common among other students. When students write their theses, they may have to search the references from abroad. During this process, they will improve their 
reading skills to find the information they need. In this way, their motivation of studying English will increase. It was common for 3rd and 4 th grade students.

I think English is just like a tool. Sometimes when I write a dissertation, I will refer to some English theses. At that time, I must figure out what they are talking about. (Student $G$ )

The findings illustrate the view that most participants seem English as a tool. By using English, they can obtain some short-term or long-term goals. The goal might just be understanding the meaning of words or sentences, or achieving the qualification of English level. However, there is no denying that those objects will help reduce the demotivation.

\subsubsection{Tools}

Tools are the devices that humans use to act on the physical world (Vygotsky, 1978). In the interviews, several tools were found to have probably affected demotivation such as textbooks, learning materials and learning environment. As for these elements that would change in different academic years, the demotivation of students would also change.

Compared to the second and the third year, most participants admitted that they had stronger demotivation in the fourth year. One important reason was no English courses, as evidenced in the following example.

Our English courses start from the first year and end up in the third year. I don't have English courses when I am a senior student. (Student D)

I don't have English courses this year (the fourth year), so I am not motivated in studying English. (Student G)

The difference of textbooks may also affect students' demotivation in studying English. When studying an interesting textbook, students may have higher motivation to study it in that semester.

Textbooks will affect my motivation in studying. Take the morning reading book for instance. If it is funny, I think I can focus on it. If it is boring, I will be sleepy. (Student D)

I think the textbook is so boring. I seldom listen to the English class. (Student B)

Tools are like the double-edged sword. Interesting, detailed, and concise textbooks will be more popular among Chinese EFL learners, while boring, complex, and plain textbooks may decrease the interest in learning English. The influence of tools may last for a whole year. It was not until the change of the tool that students had a different attitude towards learning English.

\subsubsection{Community}

Community as a social cultural context consists of multiple individuals who share the common general objectives (Chen \& Johnson, 2016). In the current study, those who have the common objectives are teachers, peers, especially classmates and roommates. Some participants are field-dependent subjects, which means that they are more likely to be influenced by their friends and environment. Student A is an obvious field-dependent EFL learner. During the first-year English study, he was affected by roommates in four of the six time-nodes.

Every time my roommates study English, I think I should study it as well. (Student A)

Likewise, student $\mathrm{D}$ had similar feeling towards roommates. But she mentioned that her roommates could not persist in learning for so long. They may set a very great goal but gave up on the half way. For the interviewee herself, her demotivation would change with her roommates' performance.

I often think whether I should study with my roommates. But I found them not stick to it. So, I did not join them. (Student D)

However, some students also argued that peers have no influence on them. They would be more likely to be affected by teachers. One participant said that her classmates once had a good attitude towards English. However, because of the irresponsible English teacher, students began to reject English teacher and then the English class.

You know, we are in the school of science and technology. Teachers do not value our English. Our English teacher has poor teaching methods and poor pronunciation. She taught us for two years, but we didn't like her very much. (Student E)

\section{Conclusion}

This study explored the changes of demotivation to learn English among 15 non-English major students of 10 technological universities in China from the perspective of Activity Theory. As shown in the study, stronger demotivation among the 15 participants would be more likely to be observed in the first and fourth year during 
the four-year college time. Within an academic year, students' demotivation would be more likely to vary from an ordinary level (Neither Weak Nor Strong) to Weak. The dynamics of the respondents' demotivation is related to such factors as subject (Interest and future career), object (English examinations), tools (textbooks) and community (peers and teachers).

This study enriches current literature of demotivation studies from the activity perspective. The findings are implicative for teachers and students to tackle demotivation in English class for students if technological universities in China and other international EFL contexts. By investigating the situation of students' demotivation, teachers may understand how to improve the students' motivation and what strategies can be used to minimize the negative effect of demotivation.

Similar studies can be launched in other contexts where English serves as a foreign or second language. However, cautions are to be noted when generalizing the findings of the present study, for it only selected 15 students from ten technological universities in China. Future studies are suggested to incorporate larger body of participants for a wider representativeness. Additionally, further studies can also focus on the same group and see how the demotivation varies after college education.

\section{Acknowledgements}

We would like to thank all students for their participation in the interviews.

This study is supported by The Eighth Batch of China Foreign Language Education Fund (ZGWYJYJJ2016B54), Chinese University Research Projects of Foreign Language Instruction (2016HB0051A), Hubei Provincial Department of Education Humanities and Social Sciences Research Project (17Q064), Doctoral Research Start-up Fund of Hubei University of Technology (BSQD14062).

\section{References}

Cai, J., \& Hou, X. (2013). A Study of Factors Demotivating College Students in their English Learning. English Teachers, (7), 14-22.

Chen, Y., \& Johnson, L. (2016). Project-based Language Learning: An Activity Theory Analysis in SOE Language Learning. Overseas English, (10), 215-217.

Dörnyei, Z., \& Ottó, I. (1998). Motivation in Action: A Process Model of L2 Motivation. Working Papers in Applied Linguistics, (4), 43-69.

Engeström,Y. (1987). Learning by Expanding: An Activity-Theoretical Approach to Developmental Research. Helsinki: Orienta-Konsultit Oy.

Falout, J., Elwood, J., \& Hood, M. (2009). Demotivation: Affective States and Learning Outcomes. System, 37, 403-417. https://doi.org/10.1016/j.system.2009.03.004

Gao, X. L. (2014). An Investigation into Demotivation to Learning English among University Students. Jiangsu Foreign Language Teaching and Research, (4), 1-5.

Gorham, J., \& Christophel, D. M. (1992). Students' Perceptions of Teacher Behaviors as Motivating and Demotivating Factors in College Classes. Communication Quarterly, 40(3), 239-252. https://oi.org/10.1080/01463379209369839

Gorham, J., \& Millette, D. M. (1997). A Comparative Analysis of Teacher and Student Perceptions of Sources of Motivation and Demotivation in College Classes. Communication Education, 46, 245-261. https://doi.org/10.1080/03634529709379099

Hamada, Y. (2008). Demotivators for Japanese Teenagers. Journal of Pan-Pacific Association of Applied Linguistics, 12(2), 1-23.

Hu, R. J. S. (2011). The Relationship between Demotivation and EFL Learners' English Language Proficiency. English Language Teaching, 4(4), 88-96. http://dx.doi.org/10.5539/elt.v4n4p88

Kikuchi, K. (2017). Reexamining Demotivators and Motivators: A Longitudinal Study of Japanese Freshmen's Dynamic System in an EFL Context. Innovation in Language Learning \& Teaching, (2), 128-145. http://dx.doi.org/10.1080/17501229.2015.1076427

Kim, K. J. (2009). Demotivating Factors in Secondary English Education. English Teaching, 64(4), 249-267. https://doi.org/10.15858/engtea.64.4.200912.249

Kim, T. Y. (2011). Sociocultural Dynamics of ESL Learning (De)Motivation: An Activity Theory Analysis of Two Adult Korean Immigrants. The Canadian Modern Language Review, 67(1), 91-122. 
https://doi.org/10.15858/engtea.64.4.200912.249

Kim, T. Y., \& Kim, Y. K. (2013). Reconceptualizing L2 Learning Demotivation from a Vygotskian Activity Theory Perspective. English Teaching, 68(4), 141-163. https://doi.org/10.15858/engtea.68.4.201312.141

Kim, T. Y., \& Kim, Y. K. (2015). Elderly Korean Learners' Participation in English Learning Through Lifelong Education: Focusing on Motivation and Demotivation. Educational Gerontology, 41(2), 120-135. http://dx.doi.org/10.1080/03601277.2014.929345

Leont'ev, A. N. (1981). The Problem of Activity in Psychology. In J. V. Wertsch (Ed.), The Concept of Activity in Soviet Psychology (pp. 37-70). Armonk, NY: M.E. Sharpe.

Li, C. L. (2014). A Study on Demotivation to Learn English among Senior Middle School Students in the Chinese EFL Context. Journal of Basic English Education, (1), 3-10.

Li, C. L. (2015). On the Theoretical Construction of Negative Impetus in Foreign Language Learning based on the Perspective of Activity Theory. English Teachers, (8), 45-50.

Li, C. L. (2016). A Comparative Study on Demotivation to Learn English between Senior and Junior Middle School Students. English Language Teaching and Research in Primary and Middle Schools, (1), 23-28.

Li, C. L., \& Zhou, T. (2017a). A Questionnaire-based Study on Chinese University Students' Demotivation to Learn English. English Language Teaching, 10(3), 128-135. https://doi.org/10.5539/elt.v10n3p128

Li, C. L., \& Zhou, T. (2017b). An Exploratory Study on the Relationship between Demotivation and Academic Fields among Chinese EFL Learners. Arab World English Journal, 8(1), 42-54. https://dx.doi.org/10.24093/awej/vol8no1.4

Liu, N., \& Liu, H. G. (2016). An Empirical Research on Demotivators in Senior High School Students' English Learning. Basic Foreign Language Education, 18(2), 3-12.

Najafi, F., \& Behjat, F. (2013). The Rise and Fall of Iranian Female Students' Motivation at Different Levels of Language Proficiency from High School to University [J]. International Journal of Language and Linguistics, 1(4), 166-177. https://doi.org/10.11648/j.ijl1.20130104.21

Qin, L. L., \& Dai, W. D. (2013). A Study on College English Learning Motivation Self System Model Framed by the Activity Theory. Foreign Language World, (6), 23-31.

Rashidi, N., Rahimi, M., \& Alimorad, Z. (2014). Iranian University English Learners' Discursive Demotivation Construction. Iranian Journal of Language Teaching Research, 2(2), 35-49.

Sakai, H., \& Kikuchi, K. (2009). An Analysis of Demotivators in the EFL Classroom. System, 37, 57-69. https://doi.org/10.1016/j.system.2008.09.005

Tsang, S. Y. (2012). Learning Japanese as a Foreign Language in the Context of an American University: A Qualitative and Process-Oriented Study on De/Motivation at the Learning Situation Level. Foreign Language Annals, 45(1), 130-163. https://doi.org/10.11648/j.ijl1.20130104.21

Vygotsky, L. S. (1978). Mind in Society: The Development of Higher Psychological Processes. Cambridge, MA: Harvard University Press.

Wu, Z. (2002). Teachers' "Knowledge" and Curriculum Change: A Critical Study of Teachers' Exploratory Discourse in a Chinese University. Perspectivas Em Ciência Da Informação, 14(2), 187-203.

Yu, S. L. (2013). Revisiting teacher feedback and peer feedback: A sociocultural activity-theory perspective. Modern Foreign Languages, (1), 70-76.

\section{Copyrights}

Copyright for this article is retained by the author(s), with first publication rights granted to the journal.

This is an open-access article distributed under the terms and conditions of the Creative Commons Attribution license (http://creativecommons.org/licenses/by/4.0/). 